\title{
CRYSTALLIZATION FORCE OF SODIUM CHLORIDE
}

\author{
V. Koudelková*, B. Wolf**
}

\begin{abstract}
Soluble salts are one of the most deteriorating factor causing damage of historical building materials due to generation of crystallization pressure inside pore space. Direct measurement of crystallization force is quite challenging, hence we developed at our institute a novel device able to detect the force of growing crystal. The device is based on the monitoring of force developed with upper microscopic glass on the growing crystal to maintain constant position. The crystal could generate force because of the existence of thin liquid layer of solution between both surfaces come into contact. The driving force for the subsequent growth of crystal against obstacle is supersaturation, which is mainly induced by evaporation of the salt solution. In this experiment, the crystal of sodium chloride generated force $16.8 \mathrm{mN}$ and the corresponding crystallization pressure was equal to the value $0.48 \mathrm{MPa}$.
\end{abstract}

Keywords: crystallization force, sodium chloride, salt deterioration

\section{Introduction}

Water-soluble salts are one of the most deteriorating factor causing damage of historical building materials. Damage caused by salt action consists in generation of crystallization pressure in the pore space of non-metallic building materials, that are not able to withstand corresponding tensile load and progressively decay. The magnitude of crystallization pressure depends both on the supersaturation of salt solution and on the surface properties of crystal and mineral surface, since crystallization pressure is most probably the result of repulsive forces between two charged surfaces, that are pushed into contact (Scherer, 1999 and Veeramasuneni, 1997). Evaporation as well as cooling of salt solution leads to development of more concentrated solution. Once the concentration of dissolved ions exceeds the critical value, formation of nuclei starts. At favourable conditions, i.e. mainly at sufficient supply of dissolved ions, the volume of pore is filled with crystals over time. Subsequent growth of crystals against pore walls and its rate is supported by supersaturation of thin liquid layer between crystal surfaces and pore walls. The corresponding pressure related to supersaturation is expressed by equation (1).

$$
p=\frac{R T}{v_{c}} \ln \left(\frac{Q}{K}\right)
$$

Where $R, T$ and $v_{c}$ are gas constant, temperature and molar volume of the crystal respectively. Supersaturation is defined as the ratio of ionic product $Q$ and equilibrium constant $K$ and could be reached in the solution in two ways - by cooling of the solution as well as due to evaporation (Flatt, 2002). Nevertheless, determination of supersaturation of solution inside the pores is difficult and possible only with special techniques such as nuclear magnetic resonance (Rijniers, 2005). In this study we focused on the measurement of crystallization force generated by growing crystal of $\mathrm{NaCl}$, since it is the most common soluble salt occurring in the historical masonries. Detection of crystallization force is quite challenging and among large number of studies dealing with behaviour of salts and its damage potential

MSc. Veronika Koudelková: Institute of Theoretical and Applied Mechanics CAS, v.v.i., Prosecká 809/76; 190 00, Prague; CZ, koudelkova@itam.cas.cz

** Benjamin Wolf: Institute of Theoretical and Applied Mechanics CAS, v.v.i., Prosecká 809/76; 190 00, Prague; CZ, wolf@itam.cas.cz 
exist only few concerned on direct experimental measurement of this phenomenon (e.g. Hamilton, 2010, Sekine, 2011 and Desarnaud, 2016).

\section{Methods}

At our institute was developed a device constructed for the direct measurement of force generated by growing crystal of salt (Fig. 1). The whole system of the device is based on the principle of the lever. The larger lower glass serves as the base with two inserted tangs at what the upper narrower glass is manually placed. Correct insertion of upper microscopic glass indicates two diodes which could be seen on the left picture in the Fig. 1. A drop of solution is carefully placed into the gap between glasses and the force developed by electromagnets necessary for the maintenance of constant position of the upper glass is monitored (Fig. 1). Once the growing crystal fills the gap, it starts to push and change position of the upper glass. The driving force for the additional growth of crystal is supersaturation of very thin liquid film of solution which is sustained by surface forces between crystal and glass (Scherer, 1999). Force generated by electromagnets is proportional to the force developed by growing crystal. The glass is optimal material for observation of growing crystal. Moreover, the surface of glass has similar properties as the surface of mineral quartz - the main mineral composing sandstone which was one of the major building stone in the medieval ages in the Czech Republic. Both surfaces are negatively charged in aqueous salt solutions at higher $\mathrm{pH}$ (Veeramasuneni, 1997, Adler, 2001 and Liang, 2007). The system is quite sensitive, the force is monitored within the range of $\mu \mathrm{N}$ and the position of upper glass in the range of $\mathrm{nm}$. The values of position and force are monitored after $1 \mathrm{~s}$ and recorded for the whole duration of crystallization experiment.

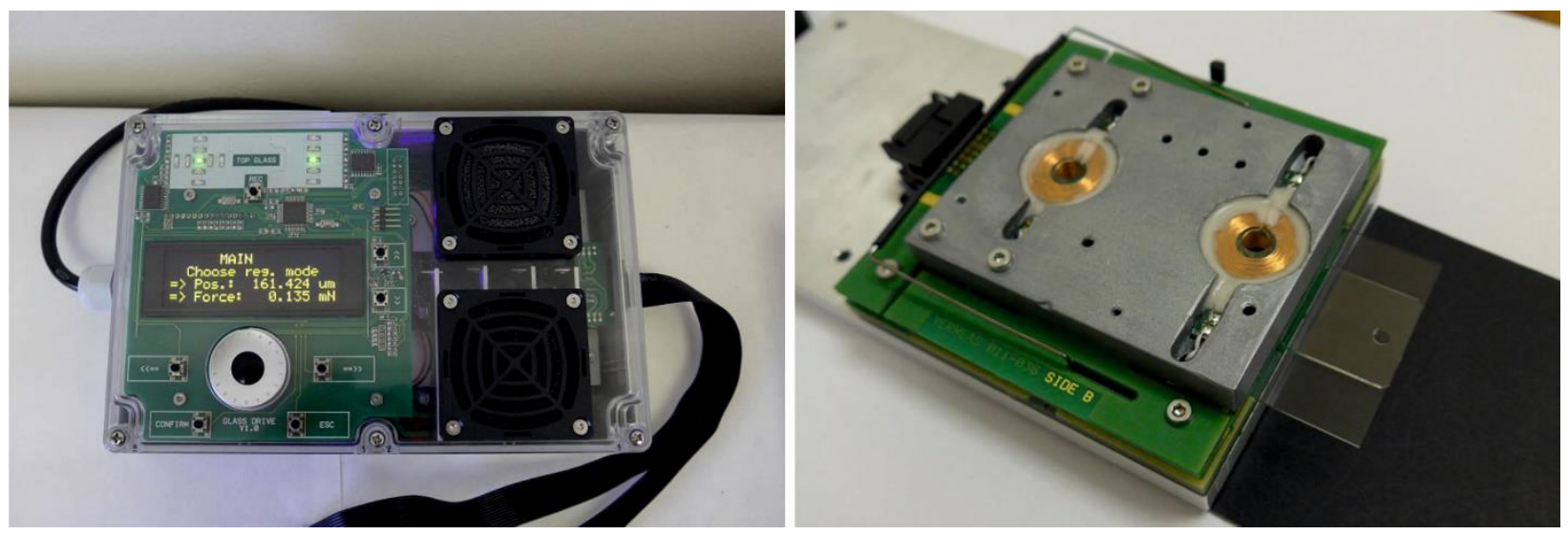

Fig. 1: The novel device constructed for direct measurement of crystallization force.

For the crystallization experiment was prepared saturated solution of $\mathrm{NaCl}$. Both microscopic glasses were cleaned with pure ethanol and washed with pure double distilled water. On the lower glass was placed small drop of solution and covered with upper glass. The size of the gap between both glasses was maintained at the value of $500 \mu \mathrm{m}$. From the diameter of the drop was then calculated initial volume of the liquid which was approximately equal to the value $9 \mu$ l. The ambient temperature and relative humidity was $25^{\circ} \mathrm{C}$ and $38 \%$ respectively.

\section{Results}

The whole duration of the experiment was approximately 4 hours. The diagram showed at the Fig. 2 represents the dependence of force (black curve) on the deviation of upper glass (gray thin curve) from the defined position (gray thicker curve). The force at the beginning and in the first one and half hour of the experiment is positive accompanied by the stronger oscillations in the position of the upper glass that are result of attractive capillary forces in the drop of solution. The positive values of force mean that the upper glass is retracted by electromagnets while the negative values are result of attraction of the upper glass in the opposite direction which leads into pushing the upper glass against obstacle to maintain the position. The principle is clearly depicted in the Fig. 3. The average value of capillary forces was equal to $7.1 \mathrm{mN}$. As the evaporation of the solution proceeds the drop diminished and the cubic crystal of $\mathrm{NaCl}$ grows. Once the crystal comes into contact with upper glass the oscillations decrease. Since the average value of real position of the upper glass is slightly above (approximately $50 \mathrm{~nm}$ ) the defined position, the 


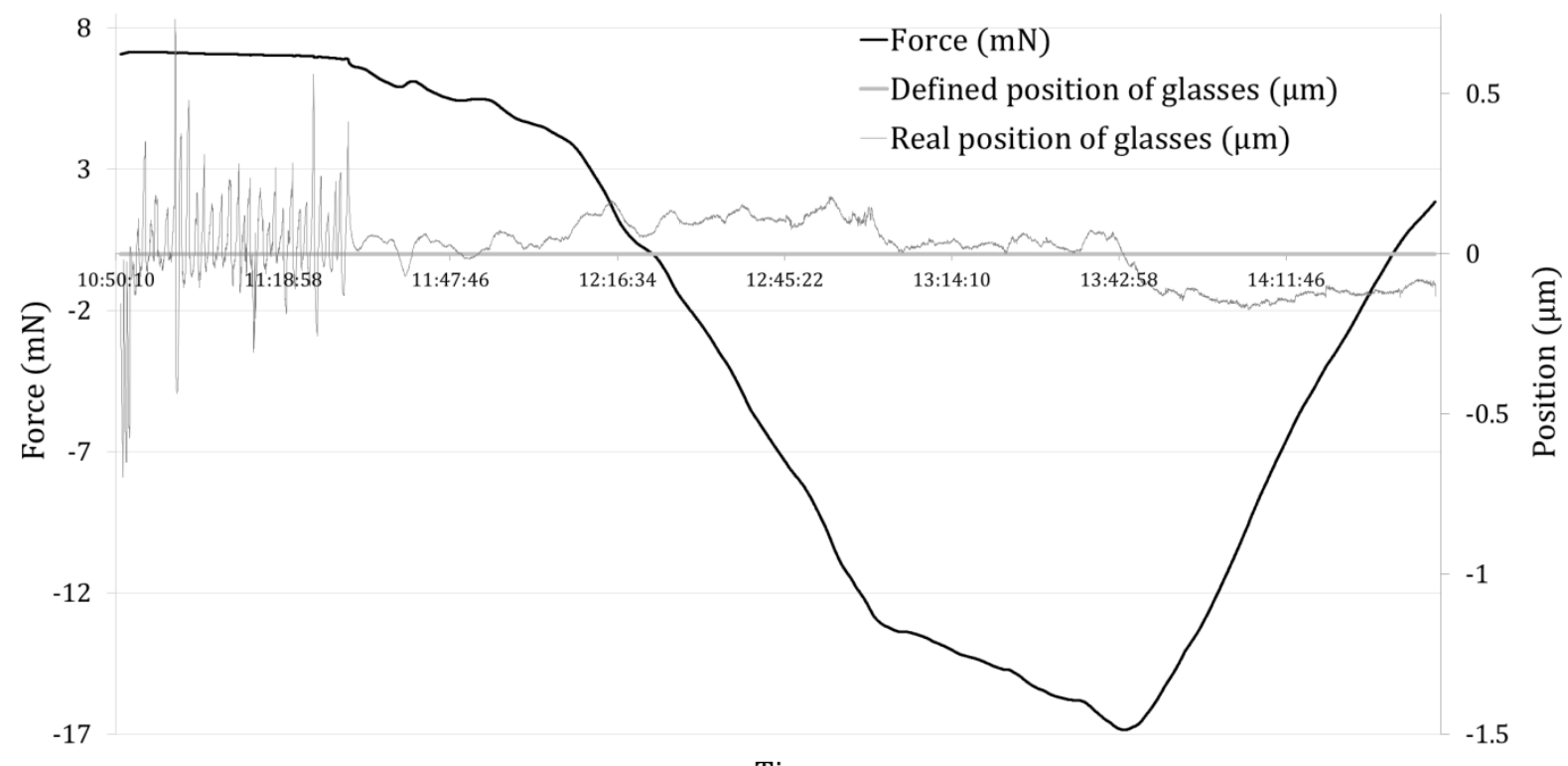

Time

Fig. 2: Force developed by growing crystal of sodium chloride.
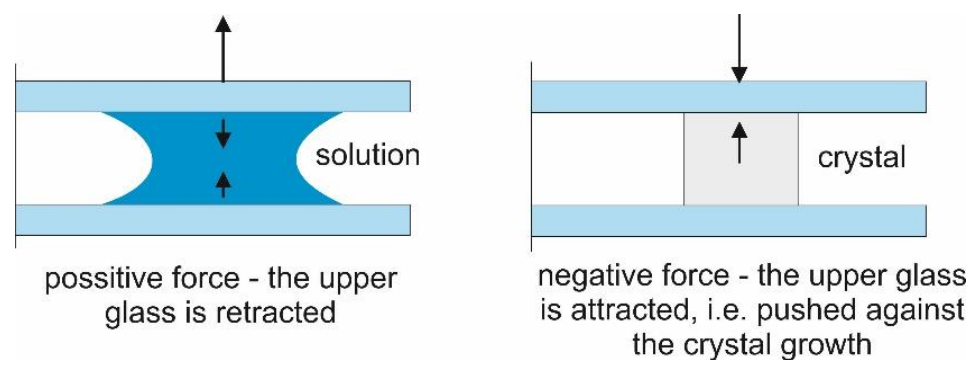

Fig. 3: Schematic diagram of the control of the position of the upper glass in the presence of solution and crystal.

force also gradually decreases. At the moment when the force proceeds into negative values, i.e. see the first intersect of force curve with the defined position curve set at the $0 \mu \mathrm{m}$ in the Fig. 2, the upper glass starts to be pushed against the crystal growth. The force gradually decreases until the minimum value $16.8 \mathrm{mN}$ is reached. This minimum responds to the force at which the growth of the crystal was suppressed. Hence, the crystallization force of $\mathrm{NaCl}$ crystal in this experiment is equal to the value 16.8 $\mathrm{mN}$. This phenomenon is indicated by the drop of real position curve under the defined position curve. Subsequent force change into positive values at the end of experiment is caused by the tendency of the system to balance upper glass on the set defined position at $0 \mu \mathrm{m}$.
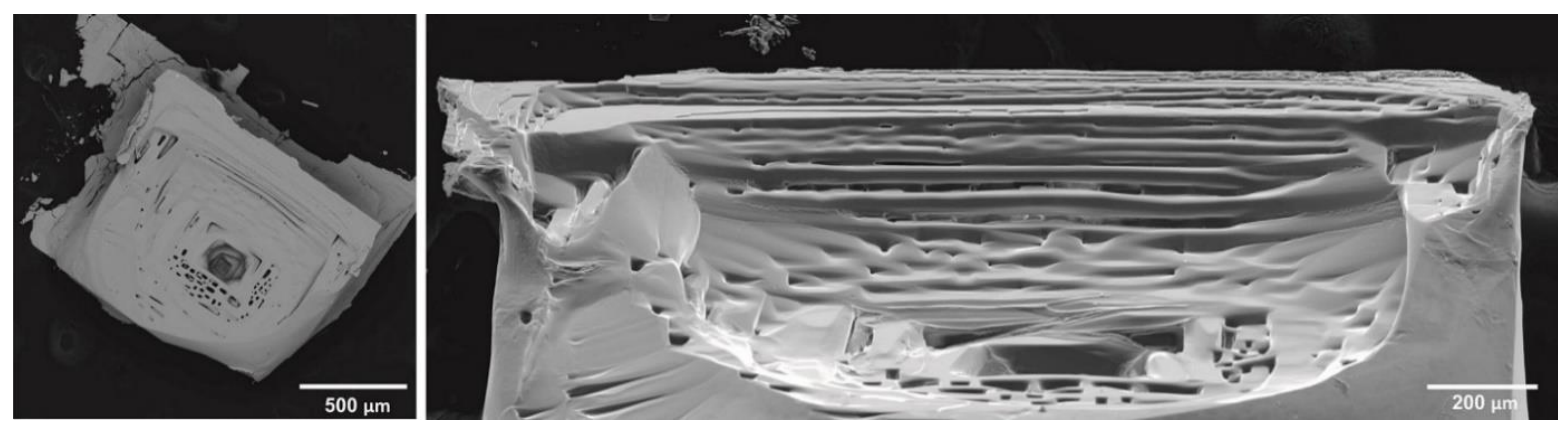

Fig. 4: Micrographs acquired in scanning electron microscope showing typical morphology of $\mathrm{NaCl}$ crystal grown under load. 
The crystal under the load commonly creates the step like morphology known as hopper crystal shape (see the Fig. 4). The contact surface with the glass is reduced on the narrow area at the periphery of the crystal (Røyne, 2012). According to image analysis performed using a common free program ImageJ the contact area was calculated to be approximately equal to $0.035 \mathrm{~mm}^{2}$. The resulting crystallization pressure corresponds to the value $0.48 \mathrm{MPa}$.

\section{Conclusion}

The fact that growing crystals are able to cause damage is phenomenon which has been known and studied for the long time. Nevertheless, there is lot of ambiguities that have to be determined and better understood, for instance the experimental quantification of crystallization pressure of different salts and their mixtures or the behavior of salts in different environmental conditions etc. Determination of crystal contact area for the calculation of crystallization pressure is very uneasy since the area is not a plane. The crystal surface at this contact is full of holes and pits in nanometer range which is difficult to observe even in scanning electron microscope (Desarnaud, 2016 and Hamilton, 2010). Based on this presumptions the crystallization pressure $0.48 \mathrm{MPa}$ calculated here is probably the lower bound of true crystallization pressure since the contact area of the crystal grown in this experiment was most likely much smaller. The measured values of force generated by different crystals of the same salt will by comparable only in case of application uniform volume of the saturated solution at the beginning of each crystallization experiment. Indeed, the experiments have to be performed at very similar ambient temperature and relative humidity conditions. A detail microscopic investigation of crystal morphology as well as the morphology of contact area will be also necessary. The behavior of crystals in-situ during future experiments will be also observed by optical microscope.

\section{Acknowledgement}

The research has been supported by Czech Science Foundation (Project no. P105/12/G059).

\section{References}

Adler, J. J., Rabinovich, Y. I. and Moudgil, M. (2001) Origins of the non-DLVO force between glass surfaces in aqueous solution. Journal of Colloid and Interface Science, 237, 2, pp. 249-258.

Desarnaud, J., Bonn, D. and Shahidzadeh, N. (2016) The Pressure induced by salt crystallization in confinement. Scientific Reports, 6, 30856, doi: 10.1038/srep30856.

Flatt, R. J. (2002) Salt damage in porous materials: how high supersaturations are generated. Journal of Crystal Growth, 242, 4, pp. 435-454.

Hamilton, A., Koutsos, V. and Hall, C. (2010) Direct measurement of salt - mineral repulsion using atomic force microscopy. Chemical Communications, 46, 29, pp. 5235-5237.

Liang, Y., Hilal, N., Langston, P. and Starov, V. (2007) Interaction forces between colloidal particles in liquid: Theory and experiment. Advances in Colloid and Interface Science, 134, 1, pp. 151-166.

Rijniers, L. A., Pel, L., Huinink, H. P. and Kopinga, K. (2005) Salt crystallization as damage mechanism in porous building materials - a nuclear magnetic resonance study. Magnetic Resonance Imaging, 23, 2, pp. 273-276.

Røyne, A. and Dysthe, D. K. (2012) Rim formation on crystal faces growing in confinement. Journal of Crystal Growth, 346, 1, pp. 89-100.

Scherer, G. W. (1999) Crystallization in pores. Cement and Concrete Research, 29, 8, pp. 1347-1358.

Sekine, K., Okamoto, A. and Hayashi, K. (2011) In situ observation of the crystallization pressure induced by halite crystal growth in a microfluidic channel. American Mineralogist, 96, 7, pp. 1012-1019.

Veeramasuneni, S., Yalamanchili, M. R. and Miller, J.D. (1997) Interaction forces at high ionic strengths: The Role of polar interfacial interactions. Journal of Colloid and Interface Science, 188, 2, pp. 473-480. 